\title{
Impact of Emotional Intelligence and Motivation on Job Satisfaction among "Mystery Shoppers"
}

Anand Shankar Raja M $^{*}$

\begin{abstract}
This research paper focuses on "Mystery Shopping", making mystery shoppers the target respondents of this research study. While previous studies have taken into consideration the motivational aspect, this research extends the scope to consider EI and its mediation between motivation and job satisfaction. Simple percentage analysis has been used to analyse the demographic profile of the respondents as well as an Exploratory Factor Analysis (EFA) and corresponding CFA. The hypothesized eleven factors of CFA (4 factors for motivation, 5 factors for Emotional Intelligence and 2 factors for job satisfaction) model fits the sample data very well. The major rule of thumb RMSEA is .87, RMR is 0.30 and AGFI is .891 which has satisfied the CFA model fit criteria. It is found that job satisfaction is enhanced only through motivation directly rather than being mediated by EI. Thus the lacking aspects have to be considered by the mystery shoppers to enhance job satisfaction through a well-balanced emotional state.
\end{abstract}

Keywords: Mystery Shoppers, Job Satisfaction, Motivation, Emotional Intelligence

* Christ University, Bangalore, India; anand.shankar@christuniversity.in 


\section{Introduction}

Mystery shopping is also known as ghost shopping, is the sister concept of marketing research. Mystery shopping, in simple words, is an observational tool used to measure various dimensions of service quality. The observed details are converted into written records and the same is submitted to the top management to facilitate better decision making. The mystery Shopping (MS) method is employed in marketing research to allow for the measurement of consumer provision levels and may contain both quantitative and qualitative components.

\section{Review of literature}

Lisa J Morrison, Andrew \& Carolyn (1997) focused on the memory of mystery shoppers and stated that the mystery shopping procedure makes considerable demands on the assessor's memories and therefore there are problems that might arise from failure of memory. Kallol Saha (2009) examined mystery shopping as a market research tool to measure customer satisfaction, and concluded that mystery shopping is the most effective and unbiased tool to ensure the level of customer satisfaction. Tamer Mohamed Atef (2012), concentrated on hospitality operations and aims to measure the quality of services and products delivered to their customers, thus placing emphasis on service quality. Dr. R. Angayarkanni and Anand Shankar Raja M, in their research work, have clearly mentioned that "Mystery shopping is a simple concept which deals with just silent observation but the stress and pain which mystery shopper's face during each assignment is enormous". Thus, the importance of motivation, emotional intelligence and job satisfaction of mystery shoppers are to be determined in order to provide necessary steps helping them shine in their profession. R Angayarkanni and Anand Shankar Raja M have also specified the importance of Emotional Intelligence among mystery shoppers in their research paper "Emotional Intelligence an essential cause". The researchers have stated clearly that mystery shoppers should have the ability to understand others emotions. Alan M. Wilson (1997) tried to study the measurement of service delivery in service industries. Priyanka Singh, Gaurav 
Verma (2014)in a study on the mystery shopping instrument and mystery shopping audit, has stated that the key principles for the mystery shopper to work as shop audit is that the mystery shopper must be credible, practical and take safe steps. N Shibu \& J Martin (2014) strongly concluded that mystery shopping is the best tool for analysing the ideas of customers viewed at every stage, from crafting a product to the sales and after sales services. Beck and Miao (2003) investigated how mystery shopper programmes are conducted in the USA and the senior hotel management's perceptions affect the scheme's effectiveness in assessing service quality. Harvey (1998) reported on a variant of the mystery shopping program, where actual customers are trained to make detailed notes of their shopping. Wilson (2001) describes the use of mystery shopper as "using descriptions". Shing and Spence (2002) have found that mystery shopping is a means of competitor intelligence gathering. Dawson and Hiller (1995) have stated that it is a research technique which is gaining popularity and is a widely accepted concept for measuring the quality of interactions. According to Morrison et al. (1997), mystery shopping surveys utilise only small samples, up to a few visits to any outlet or only a single visit. Pamela B. Allisona \& Denver E. (2011)state that "mystery shopping" has become an accepted method of performance measurement in many industries. Scott Rooda \& Joanna Dziadkowiecb (2013) employed SERVQUAL and mystery shopping, using important performance analysis side-by-side in restaurants in two different countries. In the case of $\mathrm{W}$. Benjamin Myers (2011), the researcher has worked as a mystery shopper from the year 2004 and has quoted his own experience as an example for this study as well as drawn observations on various aspects'. W. Kelley, O. C. Ferrell and S. J. Skinner considered the relationship between perceptions of ethical behaviour and the demographic characteristics of sex, age, education level, job title, and job tenure, among a sample of marketing researchers (Spector, 2003). Research suggests that satisfied employees are time-effective at work, likely to minimize their sick leave and have lower turnover intentions (Spector, 1997). Additionally, Meyer et al. (2002) identified a significant relationship between job satisfaction and affective commitment. Other researchers have found an inverse relationship between work stress and other job-related outcomes, such as job 
satisfaction. Syet al. (2006), however, found a positive relationship between EI and job satisfaction as employees who have high EI are more likely to have higher levels of job satisfaction. This is because these employees are better at appraising and regulating their feelings. T. A. Judge and R. Ilies (2004) with regard to job satisfaction state that people who tend to be positive and cheerful most of the time do indeed tend to express higher job satisfaction than ones who tend to be down and gloomy. They also added that job satisfaction depends primarily on the match between the outcomes of an individual's value in their job and their perception about the availability of such outcomes - especially for those facets of the job that are highly valued. According to Keith Davis and John W. Newstrom (2002) job satisfaction is a set of favourable or unfavourable feelings and emotions with which employees view their work. It is an affective attitude, a feeling of relative like or dislike toward something. Job satisfaction is important for an organization's success. Much research has been conducted into ways of improving job satisfaction of workers in various sectors of the Malaysian economy, including the academic sector (Wong \& Teoh, 2009; Noordin \& Jusoff, 2009), the hotel sector (Abd.Patah, Radzi, Abdullah, Adzmy, AdliZain, \& Derani, 2009), the government sector (Yahaya, A., Yahaya, N., Arshad, \& Ismail, 2009)and the non-profit sector. The outcome of job satisfaction is based on various other factors. Spector (1997) identified nine (9) dimensions of job satisfaction, these are as follows: pay, promotion, supervision, fringe benefits, contingent rewards operating procedures (required rules and procedures), co-workers, nature of work, and communication.

\section{Theoretical connection and conceptual frame work}

Scientific knowledge is based on empirically tested theories. Thus, existing theories are constantly subjected to critical scrutiny, tests, modification and rejection. These theories help the researcher to understand the existing relationship between variables and to connect variables to form new relationships. This is a continuous process of searching for various reviews and theories to form hypotheses and work towards building a conceptual framework. Thus, such links would help the researcher contribute toward the success of the framework. The conceptual model is useful in 
analysing and communicating the essence and the effect of the variables used in the study, and for predicting the implications which could be used for betterment. The purpose of this research is to determine whether motivation and Emotional Intelligence would enhance job satisfaction among mystery shoppers. The study has been conducted after a detailed review process of various literatures and previous research. A conceptual framework has been formulated to better understand the logical link between the three study variables.

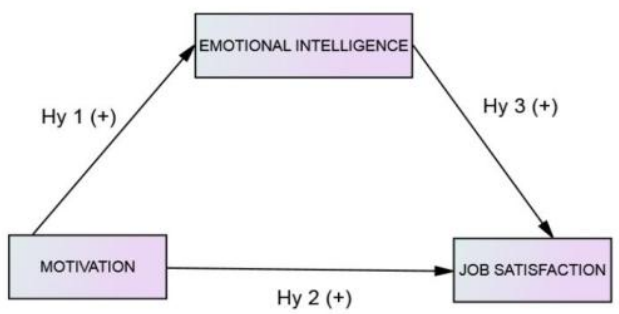

Chart No 1.0 Hypothesis development Model framework Model 1

\section{Methodology}

The research work determines the role of EI in acting as a mediator between motivation and job satisfaction. Limited time span has been considered to be within the scope of this study as mystery shoppers migrate to various other firms and hence there is no quantifiable fixed population. This study collects first-hand information from mystery shoppers using a questionnaire schedule and hence it constitutes primary data. At the same time, the existing data from reputed databases and other secondary sources has been used effectively. Thus, the researcher relies on both primary and secondary data. Since the mystery shopping population within a market research agency is never isolated, it keeps fluctuating as there are new entrants all the time. Thus initially 200 samples were drawn using convenient sampling method and the remaining target respondents of 38 were brought into consideration using snowball sampling. Mystery shoppers in the city of Chennai are considered as the primary population for this research study as Chennai was selected as the study area for this research. In this research work multi-scales are checked for 
reliability analysis with the help of SPSS version 16 . The test results range from .72 to .88 for different segments of research instrument, indicating that it is reliable. A commonly accepted rule for describing internal consistency using Cronbach's alpha has been satisfied.

\section{Analysis and interpretation}

The demographic profile of the respondents depicts clearly that $(68.5 \%)$ of the mystery shoppers fall in the age group of 18-46. It must be noted that almost $(16.4 \%)$ of the mystery shoppers are senior citizens. With regards to gender, the mystery shoppers are predominantly male, with $(71.8 \%)$ of the respondents being men. $(64.3 \%)$ of the mystery shoppers are unmarried and only $(13.0 \%)$ of the mystery shoppers earn between Rs 31000 to 43000 . The majority of mystery shoppers (24.8\%) are undergraduates. It has been found that only $(8.0 \%)$ of the mystery shoppers are government servants and majority of the mystery shoppers $(34.9 \%)$ list business as their main occupation. Majority (67.2\%) of the mystery shoppers belong to nuclear families and a considerable percentage $(55 \%)$ of the mystery shoppers belong to a family which has 5 family members. Most $(70.2 \%)$ of the mystery shoppers live in urban areas. Some of the respondents $(40.3 \%)$ choose to take up mystery shopping as a hobby as it involves more personal enthusiasm. Only a very few $(11.8 \%)$ have told that they get mystery shopping assignments rarely. Regarding experience in the field of mystery shopping only $(17.2 \%)$ of the mystery shoppers have an experience of over 6 years. A majority of the mystery shoppers the most influencing problem is dozens of schedule represented by $(17.2 \%)$ of the respondents.

\section{Exploratory Factor Analysis (EFA)}

After screening through the sample size and adequacy of 238respondents, the research was conducted using Kaiser-MeyerOlkin (KMO) \& the Bartlett's test which specified the reasonable basis for a factor analysis to check the interlink between the variables. The results for SSREI, WEIMS \& GJSS clearly portrayed that the sample adequacy norms were met and the variables used in the analysis were highly correlated with each other. Almost all the scale items had a good communality range as shown under 
extraction, excepting a few which were removed from being clubbed for the allocation of an appropriate name.

After the rotated component analysis, the components of SSREI (33 scale constructs) were clubbed into appropriate heads such as

I. Optimistic representing Component 1

II. Empathetic emotions representing component 2

III. Combating Negativities representing component 3

IV. Accompanying others' emotions representing component 4 and,

V. Self-Apprehension representing component 5

VI. With regard to the WEIMS after the rotated component analysis the components (18 scale constructs) were clubbed into appropriate heads such as

I. Motivation for Triumph representing component 1

II. Motivation to be a front-runner representing component 2

III. Motivation for Livelihood representing component 3 and,

IV. Feeling Secured representing component 4

The GJSS scale (10 item constructs) after the rotated component analysis was clubbed based on the factor loadings and iteration. The following names were allotted:

I. Refreshed sensation representing component 1

II. Acclaim and confident representing component 2

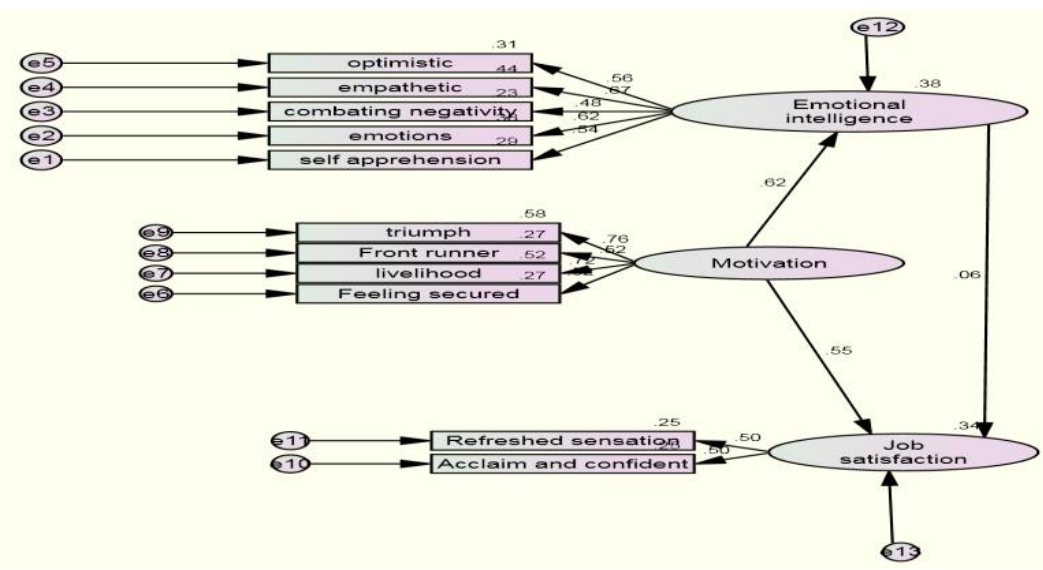

Structural Equation Model (confirmatory factor analysis) 
Table No 1.1 Selected AMOS output; Parameter estimates

\begin{tabular}{|c|c|c|c|c|c|c|c|}
\hline & & & Estimate & S.E. & C.R. & $\mathrm{P}$ & Label \\
\hline $\begin{array}{l}\text { Emotional } \\
\text { intelligence }\end{array}$ & $<--$ & Motivation & .707 & .101 & 6.975 & $* * *$ & \\
\hline $\begin{array}{l}\text { Job } \\
\text { satisfaction }\end{array}$ & $<---$ & $\begin{array}{l}\text { Emotional } \\
\text { intelligence }\end{array}$ & .073 & .133 & .548 & .584 & \\
\hline $\begin{array}{l}\text { Job } \\
\text { satisfaction }\end{array}$ & $<--$ & Motivation & .707 & .176 & 4.018 & $* * *$ & \\
\hline F5 & $<---$ & $\begin{array}{l}\text { Emotional } \\
\text { intelligence }\end{array}$ & 1.000 & & & & \\
\hline $\mathrm{F} 4$ & $<---$ & $\begin{array}{l}\text { Emotional } \\
\text { intelligence }\end{array}$ & 1.151 & .127 & 9.061 & $* * *$ & \\
\hline F3 & $<---$ & $\begin{array}{l}\text { Emotional } \\
\text { intelligence }\end{array}$ & .876 & .113 & 7.740 & $* * *$ & \\
\hline F2 & $<---$ & $\begin{array}{l}\text { Emotional } \\
\text { intelligence }\end{array}$ & 1.150 & .123 & 9.385 & $* * *$ & \\
\hline F1 & $<---$ & $\begin{array}{l}\text { Emotional } \\
\text { intelligence }\end{array}$ & 1.137 & .133 & 8.573 & $* * *$ & \\
\hline MC4 & $<---$ & Motivation & 1.000 & & & & \\
\hline MC3 & $<---$ & Motivation & 1.288 & .132 & 9.785 & $* * *$ & \\
\hline MC2 & $<--$ & Motivation & 1.343 & .163 & 8.249 & $* * *$ & \\
\hline MC1 & $<--$ & Motivation & 1.304 & .131 & 9.934 & $* * *$ & \\
\hline JS2 & $<--$ & $\begin{array}{l}\text { Job } \\
\text { satisfaction }\end{array}$ & 1.000 & & & & \\
\hline JS1 & $<--$ & $\begin{array}{l}\text { Job } \\
\text { satisfaction }\end{array}$ & 1.022 & .215 & 4.762 & $* * *$ & \\
\hline
\end{tabular}

From the above analysed results all the above estimates are significant, except for the factor covariance between Emotional Intelligence and Job satisfaction

Table No 1.2 Standardized Regression Weights

\begin{tabular}{lllr}
\hline $\begin{array}{l}\text {.HL } \\
\text { LL. }\end{array}$ Lowest loading & & & Estimate \\
\hline $\begin{array}{l}\text { Emotional } \\
\text { intelligence }\end{array}$ & $<---$ & Motivation & .620 \\
Job satisfaction & $<---$ & Emotional intelligence & .064 \\
Job satisfaction & $<---$ & Motivation & .545 \\
E5 & $<---$ & Emotional intelligence & .541 \\
E4 & $<---$ & Emotional intelligence & .617 \\
E3 LL & $<---$ & Emotional intelligence & .477 \\
E2 HL & $<---$ & Emotional intelligence & .665 \\
E1 & $<---$ & Emotional intelligence & .559 \\
\hline
\end{tabular}




\begin{tabular}{lllll}
\hline MT4 & LL & $<---$ & Motivation & .515 \\
MT3 & HL & $<---$ & Motivation & .719 \\
MT2 & & $<--$ & Motivation & .519 \\
MT1 & $<---$ & Motivation & .760 \\
JS2 & & $<---$ & Job satisfaction & .497 \\
JS1 & HL & $<---$ & Job satisfaction & .500 \\
\hline
\end{tabular}

After running the Exploratory Factor Analysis (EFA), Emotional Intelligence factors were named based on the meaningful clubbing of various factors. Optimistic (E1), Empathetic emotions (E2), Combating Negativities (E3), Accompanying others emotions (E4) and Self-Apprehension (E5) were clubbed under Emotional Intelligence. Based on the estimated value from the model framework and the AMOS results it can be inferred that out of the five dimensions, E2 (Empathetic emotions) has a greater contribution toward Emotional Intelligence and the least contributing variable is (E3) representing Combating negativities. EFA output results were clubbed based on the factor loadings and iteration split-up and the dimensions were allotted with names such as Triumph (MT1), front-runner (MT2), Livelihood (MT3), \& Feeling Secured (MT4). From the above table it is clear that MT3Motivation for livelihood is the most significant factor contributing towards motivation and the least contributing factor is Feeling Secured. Finally with regard to job satisfaction, Acclaim and Confidence (JS2) and Refreshed sensation are the two contributing factors.

\section{Model Fit Summary}

In the table 1.2, the analysed results are compared with the Goodness-of-fit-index mentioned by various researchers and inference has been drawn.

Table No 1.3 Goodness of Fit index (GFI) for the hypothesized model

\begin{tabular}{lll}
\hline \multicolumn{1}{r}{ Fit statistics } & \multicolumn{1}{c}{ obtained } & \multicolumn{1}{c}{ Recommended } \\
\hline$\nabla^{2}$ & 195.664 & - \\
$\mathrm{df}$ & 41 & - \\
$\nabla^{2}$ Significance & 0.000 & $\mathrm{p}<=0.05$ \\
$\nabla^{2} / \mathrm{df}$ & 4.772 & $>0.90$ \\
GFI & .933 & $>0.90$ \\
AGFI & .891 & $>0.90$ \\
NFI & .834 & $>0.90$ \\
\hline
\end{tabular}




\begin{tabular}{lll}
\hline RFI & .777 & $>0.90$ \\
CFI & .862 & $>0.90$ \\
TLI & .815 & $>0.90$ \\
RMSEA & .087 & $<0.05$ \\
RMR & .030 & $<0.02$ \\
\hline
\end{tabular}

Hence the model shows an overall acceptable fit. The model is an over identified model. The confirmatory factor analysis indicated an acceptable overall model fit and therefore, the theorized model fit well with the observed data. It may be concluded that the hypothesized eleven factor of CFA (4 factors for motivation, 5 factors for Emotional Intelligence and 2 factors for job satisfaction) model fits the sample data very well.

In this research article the final hypothesis (Null hypothesis has been retained) is a type 2 error. A simple type II error is defined as failing to detect an effect that is present. The past studies and literature work of many previous researchers indicate clearly that there is a very strong association between motivation and job satisfaction and Emotional Intelligence and job satisfaction. But this entire hypothesis has been framed for other professionals. For other professions, motivation and EI would enhance job satisfaction strongly but for mystery shoppers, the effect is different. Mystery shoppers undergo various emotional situations and at the same time they have to understand the emotions of the others that they meet and interact with over the course of the mystery shopping assignment. Since their cognitive traits are being affected, the level of EI contributes less towards job satisfaction when compared to motivation. This is the reason the Null hypothesis has been retained.

\section{Conclusion}

The study provides evidence that mystery shopper's motivational levels play an important role in enhancing job satisfaction, rather than Emotional Intelligence. This negative aspect can be overcome by mystery shoppers by increasing their emotional qualities which would help them to cope with their emotional factors in order to attain a better career satisfaction. Cheering up during tough times and being more enthusiastic helps mystery shoppers to combat 
negative emotions. On the other hand, they must understand other people's emotional state and participate in sharing their feelings through effective communication. It is important for mystery shoppers to first understand that their profession is unique and it differs entirely from other professions which enjoy certain factors such as relationships with co-workers, appraisals and recognition. This job-setup, if well understood by the ghost shoppers in a positive way, will help them to maintain a healthy balanced mental state and be emotionally fit which will allow them to carve new opportunities in their career paths and become perfect mystery shopping professionals. The most important aspect to enhance job satisfaction through Emotional Intelligence is to be happy and joyful because job satisfaction is all about being happy with the task being performed. The results show that Mystery shoppers' Emotional Intelligence has a negative effect in rendering job satisfaction can be rectified by keeping oneself happy through utilizing skills and talents that would let them earn well and keep them secure in their profession. This happiness would better enhance career satisfaction rather than motivational dynamics.

\section{Suggestions}

Emotions and emotion management is a prominent feature of organizational life. It is crucial "to create a publicly observable and desirable emotional display as part of a job role." But since a mystery shopper has no organisational climate, co-relationship with workers, no appreciation and no recognition for the hard work, it increases their levels of stress, fear and anger. This results in a negative impact on job satisfaction. For a profession such as mystery shopping where it is not appropriate for emotions to be freely expressed, the increased level of job satisfaction through emotional intelligence remains an unanswered question. But this can be rectified by the mystery shoppers themselves through corrective actions. A few corrective actions which mystery shoppers may follow are:

- To take a strong action in controlling the level of stress

- To identify various negative points throughout the day and to act accordingly 
- To celebrate positive results without expecting external recognition

- To empathize with others' feelings

- To actively listen to the self during decision making

- And most importantly, to practice responding rather than reacting.

Motivation is the basis of emotional fitness. Along with motivation, Emotional Intelligence has to be given priority by the mystery shoppers.

\section{Limitations of the study}

Although the research delivered valid conclusions and findings, there are several limitations associated with the study. It is necessary to acknowledge the study's limitations as they can be used by future researchers to conduct a better study. The main objective of this research process was to determine whether motivation and Emotional Intelligence would enhance job satisfaction of mystery shoppers, thus the connecting link between these three study variables is a comfortable assumption. The noteworthy truth is that this study on mystery shoppers is a limited research study. Research work could be done to explore other variables related to various fields. Evidently, the tools used for analysis have their own technical biases and thereby impact the findings accordingly. The fresh data collected using the primary method contains respondent biases. Moreover the study focuses only on the mystery shoppers leaving the other dimensions regarding a market research agency. As the target respondents are external mystery shoppers, the internal mystery shoppers have not been not taken into consideration. The goal of the research was not to create a scale for mystery shoppers. This valid limitation can be considered by the upcoming researchers to formulate, develop and validate a scale to measure mystery shoppers' motivation, Emotional Intelligence and Job satisfaction. The research uses Explorative Factor Analysis prior to confirming the factors using a CFA. Several researchers have used the same scale in various professions, thus future researchers can take various achieved results and compare their respective results to achieve a higher 
statistical power using a meta-analysis, which was not taken up in this research thesis.

\section{Scope for future research}

There are a few neglected areas in which future researchers can take up research work. From the marketing research agency's point of view, studies can be made to determine the steps or initiatives which must be taken to make mystery shopping professionals emotionally fit and motivated and enhance their career satisfaction. Work motivation being an enigmatic topic in work and organisational management has been used in this topic as a main variable. Future research should investigate how personal characteristics may lead to different motivational orientations. Another topic for future research is the pattern of interrelationships between the work outcome variables. In addition to this, the marketing research firms train the mystery shoppers and a study can be made on training methods and its outcome on job satisfaction and other related variables. From the analysis, there are a lot of problems faced by the mystery shoppers and thus "stress management" and coping strategies to suppress the cause and effect of stress could be taken as a separate study which would contribute towards the betterment of mystery shopping professionals.

\section{References}

Abd Patah, M. O. R. (2009). The influence of psychological empowerment on overall job satisfaction of front office receptionists. International Journal of Business and Management, 04(11), 167-172.

Alan Wilson, M. A. (1997). Service industries marketing a new approach. (The Use of Mystery Shopping in the Measurement of Service Delivery). Frank Cass publishers, 148.

Angayarkanni, D. R., Prakash, \& Anand Shankar Raja, M. M., Manivannan. (2015.). A Study on the Logical Relationship between Emotional Intelligence, Job Satisfaction and Motivation among Mystery Shoppers: A Pilot Study Analysis. International Business Management,10(1), 3rd ser., 818-826.

Angayarkanni. \& Manivannan, A. S. R. (2016). Emotional Intelligence an

Essential Cause for Mystery Shoppers. International Journal of Pharmaceutical Sciences Review and Research,35(02), 186-190. 
Beck.\& Miao. (2003). Mystery shopping in lodging properties as a measurement of service quality. Journal of quality assurance in hospitality and tourism,04(12), 01-21.

Benjamin. (2011). Shopping the shopper; predictable performances and retail surveillance. Journal of performance studies,02(11), 1557-2935.

Dawson Hiller., (1995). Competitor mystery shopping; methodological considerations and implications for MRS and code of conduct. Journal of the market research society,37, 417-427.

Harvey. (1998). Service quality; A tutorial. Journals of operations management, 16(05), 583-597.

Mayer (2002). Affective, continuance, and normative commitment to the organization: A meta-analysis of antecedents, correlates, and consequences. Journal of Vocational Behaviour,61(20).

Morrison et al. (1997). Mystery customer research: cognitive processes affecting accuracy. Journal of the market research survey,39(02), 199.

Pamela B. Allisona \& Denver E. (2011). Initial and Ongoing Mystery Shopper Motivations: An Empirical Investigation by Experience Level and an Application of the Theory of Motivational Crowding. Journal of Hospitality Marketing \& Management,01(01).

Priyanka Singh, Gaurav Verma (2014). Mystery Shopping: Measurement Tool for Customer Intelligence Management. IOSR Journal of Business and Management, e-Issn: 2278-487x, p-ISSN: 2319-7668, 16(06), 101-104.

Shibu, N. \& Martin, J. (2014). A Study on Customer Experience Measurement in Retail Sales and Service Check Reliability by Mystery Shopping Method. 03(04). 